\title{
Does psychiatry need a kind of natural philosophy? As example the approach of symptom complexes in the early 20th century
}

\author{
Mauricio V. Daker \\ Universidade Federal de Minas Gerais - UFMG (retired), Brazil
}

Baconian, Galilean, Cartesian and Newtonian assumptions were overwhelming and responsible for seeing science according to materialistic premises, without much regard to life and to sentient beings. Kant also defended the priority of mathematical physics for sciences of nature, albeit in a problematic dualism with his categories of consciousness and with his concept of noumenon. Post-Kantians as Schelling tried to overcome Kant's difficulties. Schelling's natural philosophy embedded valuable concepts as autopoiesis and complex systems. Productive imagination and dialectical thinking were considered relevant to capture a creative nature, which comprises consciousness.

Schelling has been re-evaluated nowadays as a precursor of the process philosophy, which faced a revival in the early 20th century. Together with the phenomenological movement, there was a remarkable philosophical influence in psychiatry. The view of mental diseases became dynamic and more holistic in mainstream psychiatry, inquiring the real significance of mental symptom complexes. Carl Schneider's biological concept comprised the psychobiological and the somatobiological (mind and body), and he referred to symptom complexes as expressions of an always-fluid process of life with dynamic effects and changeable responsiveness, recalling Schelling and the process metaphysics. The traditional notion in psychopathology of the unitary psychosis comes again into play. Noteworthy, symptom complexes were conceived by $\mathrm{C}$. Schneider in fluid connections with normal mental functional complexes, a continuum with normality also expressed by many psychopathologists at that time.

Different from prevailing scientific mechanist, materialist and reductionist-positivistic orientation which are very much based on isolated categories of delimited and self-sufficient substances or things, process philosophy considers that what makes up the world are actual occasions. They are happenings, occurrences, or events rather than substantial entities that endure unchanged through time. They encompass action and being acted and, strikingly, they carry experiences with a subjective connotation, loaded with purpose, decision, feeling, value, satisfaction, meaning, reason. Decision or self-determination gives rise to the probabilistic laws of science and to creativity in nature, as well as to human freedom. They are internally related and not externally related as things. Nature shows itself vivid in a panexperientialism or pansubjectivism. In the living organisms, this can reach the mode of "presentation immediacy," which refers to psychism.
This different view of nature could disentangle many paradoxes or enigmas that flare up in psychiatry. Now the question about how the mind comes out of objects or matter appears less puzzling since matter itself has its origins in a nature loaded with subjectivity and meaning. In other words, a misleading metaphysics or ontology (about what is nature) leads to that recurrent unsolved or misplaced question. According to quantum physics, there has been a dematerialization of physical matter. Energy or forces are at the origins of things or matter, which are derivative. Energy forms the atoms or bricks of matter mediated by many subatomic particles (fermions, bosons and the like). Nature is primarily changeable dynamic-continuous and not static-discrete based on permanent substances. Evolution requires fundamental continuities underlying the discontinuities.

The late Kraepelin conceded the possibility that "the affective and the schizophrenic manifestation forms of insanity do not represent, in themselves, the expression of certain disease occurrences, but merely reveal those areas of our personality in which they take place." Symptom complexes would be interrelated (internally related) moments or patterns of a process, also interrelated with the normal mind, with the world and with nature in general. In this scenario, symptom complexes could be manifestations of a dynamic anthropological structure or matrix concerned with the human mind, in terms of an endogenous disposition (Figure 1). Seeing diseases as isolated self-standing substances according to a conceived static nature would not take us to speculate that far or in this way.

A whole and the interactive parts of a system

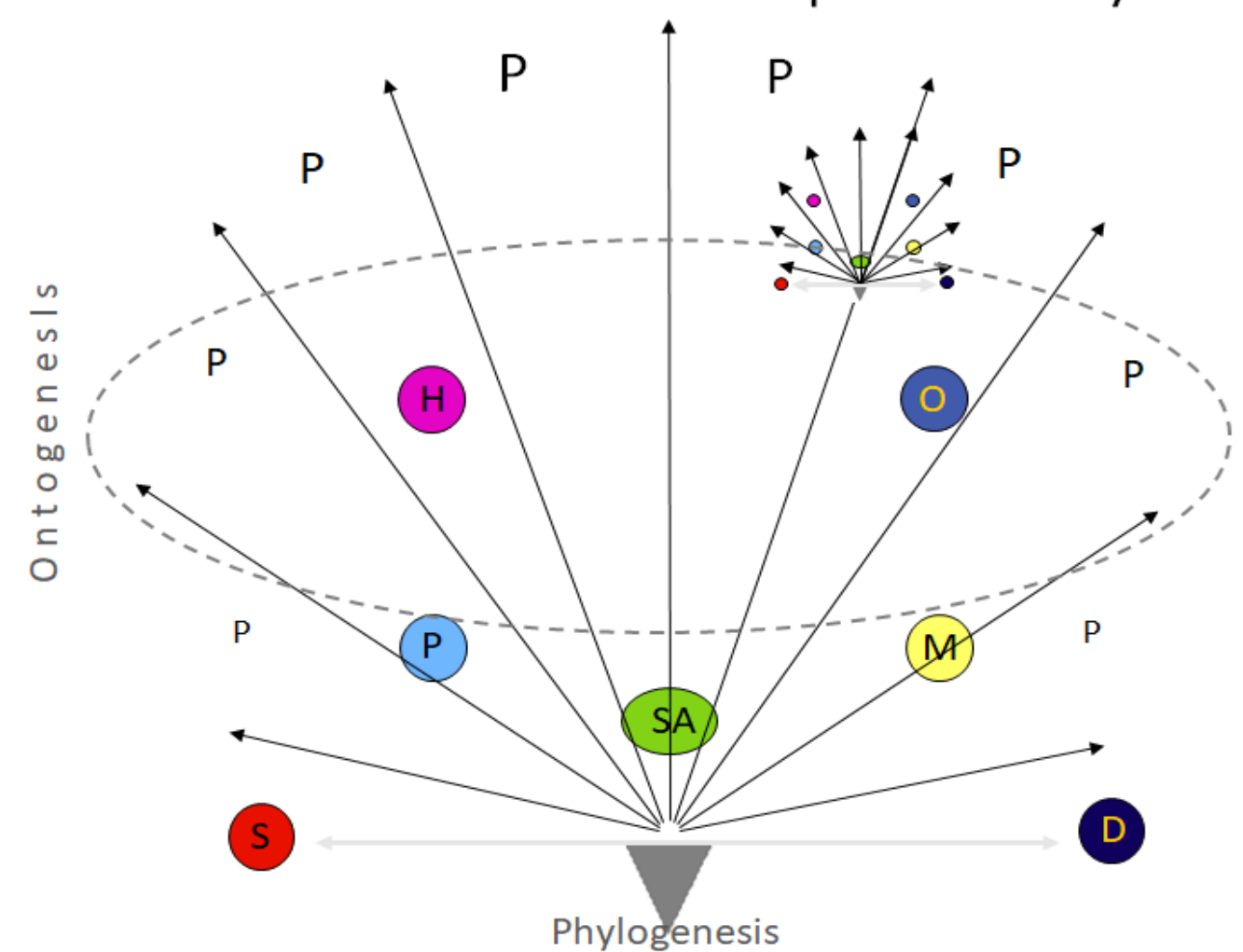

Figure 1. "General human characteristics" (Kraepelin, 1920), i.e. symptom complexes as represented here in color by their initials, and "individual $(P)$. A specific personality is exemplified at the top right.

Imagination, dialectical thinking, phenomenology, process philosophy-or a kind of natural philosophy-are necessary for sciences to approach nature, life and the human mind.

Sources: Cobb, J. B. Jr. (2015). Whitehead Word Book: A Glossary with Alphabetical Index to Technical Terms in Process and Reality. Anoka, MN: Process Century Press. / Daker, M. V. (2018). Seeing Beyond Diseases and Disorders: Symptom Complexes as Manifestations of Mental Constituents. Frontiers in Psychiatry, 9. doi: 10.3389/fpsyt.2018.00681 / Daker, M. V. (2019). The theory of symptom complexes, mind and madness. Hist Psychiatry, 30(2), 227-39. doi: 10.1177/0957154X19829671 / Daker, M. V. (Submitted). Dimensional approach in psychiatry and process philosophy: preliminary notes. Psicopatologia Fenomenológica Contemporânea. / Gare, A. (2002). Process Philosophy and the Emergent Theory of Mind: Whitehead, Lloyd Morgan and Schelling. Concrescence: The Australasian Journal of Process Thought, 3, 1-12. / Gare, A. (2018). Natural Philosophy and the Sciences: Challenging Science's Tunnel Vision. Philosophies, 3. doi: 10.3390/philosophies3040033. / Schneider, C. (1942). Die Schizophrenen Symptomverbände. Berlin, Germany: Springer-Verlag. / Seibt, J. (2018). Process Philosophy. The Stanford Encyclopedia of Philosophy. Stanford, CA. 